\title{
A Comparison of Two Land Use Simulation Models under the RCP4.5 Scenario in China
}

\author{
Feng Wu, ${ }^{1}$ Jinyan Zhan, ${ }^{1}$ Qian Xu, ${ }^{2}$ Yihui Xiong, ${ }^{3}$ and Zhongxiao Sun ${ }^{2}$ \\ ${ }^{1}$ State Key Laboratory of Water Environment Simulation, School of Environment, Beijing Normal University, Beijing 100875, China \\ ${ }^{2}$ School of Mathematics and Physics, China University of Geosciences, Wuhan 430074, China \\ ${ }^{3}$ School of Information Engineering, China University of Geosciences, Wuhan 430074, China \\ Correspondence should be addressed to Jinyan Zhan; zhanjinyan.bnu@gmail.com
}

Received 7 August 2013; Revised 13 November 2013; Accepted 13 November 2013

Academic Editor: Xiangzheng Deng

Copyright (c) 2013 Feng Wu et al. This is an open access article distributed under the Creative Commons Attribution License, which permits unrestricted use, distribution, and reproduction in any medium, provided the original work is properly cited.

\begin{abstract}
The land use simulation model is an important tool to analyze the land use/land cover change (LUCC), which plays a key role in influencing the global warming. However, there have been very few global LUCC simulation models, especially the models that can be used to analyze the interaction among the socioeconomic development, climate change, and LUCC. The Global Change Assessment Model (GCAM) and the GTAP-AEZ model are two models that take account of the influence of social economy and climate change at the global scale, but they may have some parameter errors due to the rough parameter setting. This study aims to compare the simulation results obtained with the GCAM model and GTAP-AEZ model and optimize their parameters according to the specific conditions of China. First, we simulated the land use structure in China in 2010 with the two models and compared the simulation results with the real one. Second, we calibrated these parameters of models according to the China's national conditions and implemented the simulation again. The result indicates that the calibrated GCAM can provide more accurate simulation result of land use, which can provide significant reference information for the land use planning and policy formulation to mitigate the climate change in China.
\end{abstract}

\section{Introduction}

Humans have transformed significant portions of the Earth's land surface, 10 to 15 percent of which is currently dominated by agricultural crop or urban-industrial areas, and 6 to 8 percent is pasture [1]. These land use changes have important implications for future climate changes and, consequently, great implications for subsequent land use changes [2-4]. Climate change and land use change are both global drivers of environmental change, and the impact assessments generally show that interactions between them can lead to serious challenges to the provision of ecosystem services. Besides, in many cases it is impossible to determine the impacts of climate change without consideration of land use/land cover change (LUCC). LUCC is a widespread, accelerating, and significant process, and it has been one of the research cores of the international programmes such as the International Geosphere-Biosphere Programme (IGBP) and the Global Environmental Change Human Dimensions Programme (IHDP) and is also one of the global environmental research focuses and cutting-edge issues [5]. LUCC is driven by human activities, and in many cases it also leads to changes that impact the humans; therefore, LUCC modeling is a critical way for formulating effective environmental policies and management strategies $[6,7]$. Understanding the role of land use change in the global environmental change requires the analysis of historical land cover conversions and/or projection of possible future land use changes, both of which heavily rely on the land use simulation models. Besides, the land use simulation model also provides an essential approach for stakeholder to project and evaluate the potential consequences of policy decisions and other actions. As more scholars realized the importance of LUCC, the land use simulation model has become an important tool for the analysis of both the mechanism and the spatial distribution of LUCC in the past and future $[8,9]$. The land use simulation models include Markov model, logistic function model, regression model, econometric model, dynamic systems model, spatial simulation model, linear planning 


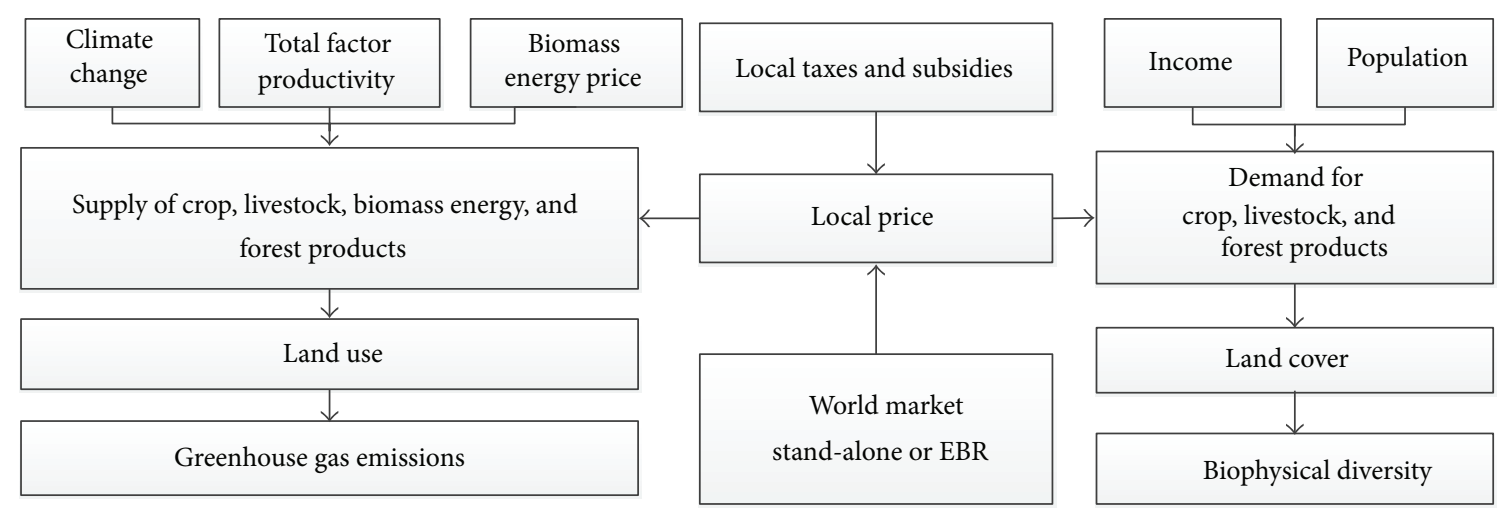

FIGURE 1: Land use allocation framework of GCAM.

model, nonlinear mathematical planning model, mechanistic GIS model, and cellular automata model [10]. All of these models may help to explore the combined effects of social policies, individual behavior, and other drivers of the land use change; however, most of them have some drawbacks. For example, the Markov model has been widely used to simulate the land use change, but it involves no spatial factors, and the land use change cannot be spatially and explicitly reflected. The CLUE-S model can comprehensively analyze the regional LUCC process and driving force, but it can only be used in the spatial allocation of land use changes so far, while the nonspatial changes must be estimated with other methods [11]. Therefore, although some models can be used to simulate land use change, there are still some serious drawbacks $[12,13]$. Moreover, there were few global models to simulate the LUCC, especially in the study of the interaction mechanism among the social economy, climate change, and LUCC. In some sense, the GTAP-AEZ model and the Global Change Assessment Model (GCAM) are more useful in the land use simulation, which can simulate the land use change of each agricultural ecological zone (AEZ), combined with the influences of social economy and climate change at global scale [14-16]. However, the parameters of these models are rough, and the simulation accuracy needs to be improved.

In the preparation for the fifth assessment report of the Intergovernmental Panel on Climate Change (IPCC AR5), the international community is developing new advanced Earth System Models (ESMs) to address the combined effects of human activities (e.g., land use and greenhouse gas emissions) on the carbon-climate system. Besides, the four representative concentration pathways (RCPs) scenarios of the future (2005-2100) have been provided by the four Integrated Assessment Model (IAM) teams, which are used as input to the ESMs for the future carbon-climate projection $[17,18]$. This study aims to compare the simulation results of land use change obtained with the GCAM and GTAPAEZ models and improve the simulation accuracy through optimizing the input parameters of the models, and the calibrated GCAM can be used to provide more accurate reference information of land use change for the land use planning and policy formulation to mitigate the climate change in China.

\section{Models}

2.1. GCAM. GCAM is a dynamic recursive model of land use and land cover, economy, agriculture, and energy, which fully integrates the energy and agriculture systems with economic equilibrium in the energy and agriculture markets [19]. GCAM consists of four modules, that is, EdmondsReilly-Barnes (ERB) model [20, 21], Agriculture and Land Use (AgLU) simulation model [22, 23], Model for the Assessment of Greenhouse-gas Induced Climate Change (MAGICC) [24], and Regional Climate Change Scenario Generator (SCENGEN) [25]. The inputs of GCAM include capital, labor, and initial land use allocation, all of which need to be provided by researchers.

The land use allocation framework shows how the land area is allocated among alternative land use types (Figure 1). The markets in GCAM are defined for energy and agricultural products, which are driven by factors such as the population, labor productivity growth, and price of resources. The land use allocation is achieved through the price mechanism in the market (Figure 1); that is, the land use allocation is based on maximization of the economic return in a region. The economic return is represented with the profit per hectare, which is the revenue (yield per hectare times price received) minus the production cost (yield per hectare times nonland cost per unit of input), as is shown in (1):

$$
\pi r_{i, l, m, p}=y_{i, l, m, p} \cdot\left(P_{i, l, m}-G_{i, l, m}\right),
$$

where $\pi r_{i l, m, p}$ is the economic return of the land measured with the profit rate $(\$ / \mathrm{ha} \cdot \mathrm{yr}), y_{i, l, m, p}$ is yield per hectare of the land use type $i$ in the AEZ $p$ (calories/ha), $P_{i, l, m}$ is the market price of the product produced by the land use type $i, G_{i, l, m}$ is the nonland cost per unit output, $i$ is an index for land use type, $l$ is the region index, and $p$ is an index for agricultural ecological zone (AEZ) within a region.

The calculation of the profit rate $(\pi r)$ of forest products is somewhat different due to the time lag between planting and harvest, and it includes a term that converts the future earnings into the present earnings as follows:

$$
\pi r_{i, l m, p}=\frac{r}{(1+r)^{45}-1} \cdot\left(\bar{P}_{i, l, m}-G_{i, l, m}\right),
$$

where $r$ is the interest rate ( $\$ / \$$, that is dimensionless). 
In order to determine the land area allocated to each land use type, the shares of land use were numerically analyzed based on the profit rates calculated with (1) and (2). Then a simplified approach was used to allocate the land area in each AEZ with the aim of maximizing the profit, with which the maximum profit rate after the land use allocation in each AEZ can be obtained, and subsequently the maximum profit which is the core of the land allocation in each AEZ can be calculated. Under the specific assumption of the functional form of the yield, the share of land use allocated to the land use type $i$ is given with a logit share equation as follows:

$$
S_{i, l, m}=\frac{\bar{\pi} r_{i, l, m}^{1 / \lambda}}{\sum_{p} \bar{\pi} r_{i, l, m, p}^{1 / \lambda}},
$$

where $\lambda$ is a positive parameter that represents the percentage change of land use in response to the change of the profit rate and $\bar{\pi} r_{i l, m}$ is the average profit rate of the land use type $i$, which is evaluated with the average or intrinsic yield $\bar{y}_{i}$ of the land use type $i$.

The land area of a specific land use type is calculated based on the total land area and the share of land use as follows:

$$
\text { Landuse }_{i, l, m}=S_{i, l, m} \cdot \text { Totalland }_{l} \text {. }
$$

2.2. GTAP-AEZ Model. The GTAP-AEZ model is based on the GTAP-E model, an extended version of the GTAP model [26], which allows for the substitution between the capital and energy and that between various fuels in sector production (Figure 2). The equilibrium solutions were worked out using the GTAP-AEZ model, with the potential future economic activities assumed based on the RCP 4.5 scenario. The inputs into the production include capital, labor, land, and other intermediate inputs, and the GTAP-AEZ model takes full account of substitutions among the input factors such as the capital, labor, and land. Besides, there is a unique production function for each land use sector in AEZs in the GTAPAEZ model, which reflects the difference of the productivity between different AEZs. For example, the productivity of the paddy rice production sector in AEZ $i$ is different from that in AEZ $j[27,28]$, and this difference can be reflected with the production function of the paddy rice production sector. Nevertheless, it is assumed that all the paddy rice sectors in the same AEZ have a homogenous productivity and ability to meet market demand.

We assume that transfer of land in a specific AEZ can occur between sectors, for which the land is more appropriate, and we believe that the introduction of the AEZ can render a sound presentation of sector competition for land. This is a new assumption beyond the standard GTAP model, in which it is assumed that the land is only transformable between sectors of crop production, livestock breeding, or timber plantation, regardless of climatic or soil constraints. However, facts show that most plants can only grow under the condition of certain temperature, moisture, soil types, land form, and so forth.

The GTAP-E model is a multisector, multiregion, and recursive dynamic computable general equilibrium model that extends the standard GTAP model through including the international capital mobility, endogenous capital accumulation, and the adaptive expectations of investment. This model is distinguished for its disequilibrium mechanism of determining the regional supply of investments. This disequilibrium mechanism includes the adjustment of the expected rate of return toward an actual return rate within each region and adjustment of the regional expected return rate toward the global return rate. These lagged adjustment mechanisms, as well as the mechanism of determining the composition of capital and allocation of wealth, are parameterized according to the econometric estimation documented by Golub (2006) [29]. In the analysis of the equilibrium of land use, it is assumed that the land is distributed among sectors for the maximization of profits in each period with similar capital and labor, although the land use does not change rapidly.

We split the total sector land rent into $18 \mathrm{AEZs}$ according to the AEZ-specific production shares derived from the data provided by the Center for Sustainability and the Global Environment (SAGE) [15] as follows:

$$
\begin{aligned}
& L_{c a}=L_{c} \cdot\left[\sum_{i \in \mathrm{SAGELANDUSE}=c} P_{i} \cdot \frac{Q_{i a}}{H_{i a}}\right.\left.\frac{H_{i a}}{\sum_{a \in \mathrm{AEZS}} \sum_{i \in \mathrm{SAGELANDUSE}=c} P_{i} \cdot Q_{i a} / H_{i a} \cdot H_{i a}}\right] \\
& c \in \text { LANDUSE; } i \in \mathrm{SAGELANDUSE} ; a \in \mathrm{AEZS},
\end{aligned}
$$

where $L_{c a}$ is the land rent accrued to the land use sector $c$ in $\operatorname{AEZ} a ; L_{c}$ is the land rent of the land use sector $c$, with no AEZ distinction; $P_{i}$ is the per-ton price of SAGE's land use type $i ; Q_{i a}$ is the production (ton) of SAGE's land use type $i$ in AEZ $a$; and $H_{i a}$ is the harvest area of SAGE's land use type $i$ in AEZ $a$. The $\sum_{i \in \text { SAGELANDUSE }}$ operator means to aggregate over the disaggregated land use type $i$ to the corresponding aggregated land use type $c$. Note that we assume that the per-ton land production price $\left(P_{i}\right)$ is homogenous across the AEZs.

\section{Scenarios}

The Integrated Assessment Models (IAMs) explored a range of technological, socioeconomic, and policy futures that could lead to particular concentration pathways and magnitudes of climate change, which is represented by the RCPs. The RCPs include four different scenarios (Table 1), that is, one mitigation scenario leading to a very low forcing level (RCP2.6), two medium stabilization scenarios (RCP4.5/RCP6), and one very high baseline emission scenario (RCP8.5), all of which could be obtained with different combinations of economic, technological, demographic, policy, and institutional futures. The development of the RCPs in the first phase allows climate modelers to proceed with experiments in parallel to the development of emission and socio-economic scenarios, expediting the overall scenario development process [18]. Coupled carbon-cycle climate models can then as well calculate associated emission levels 


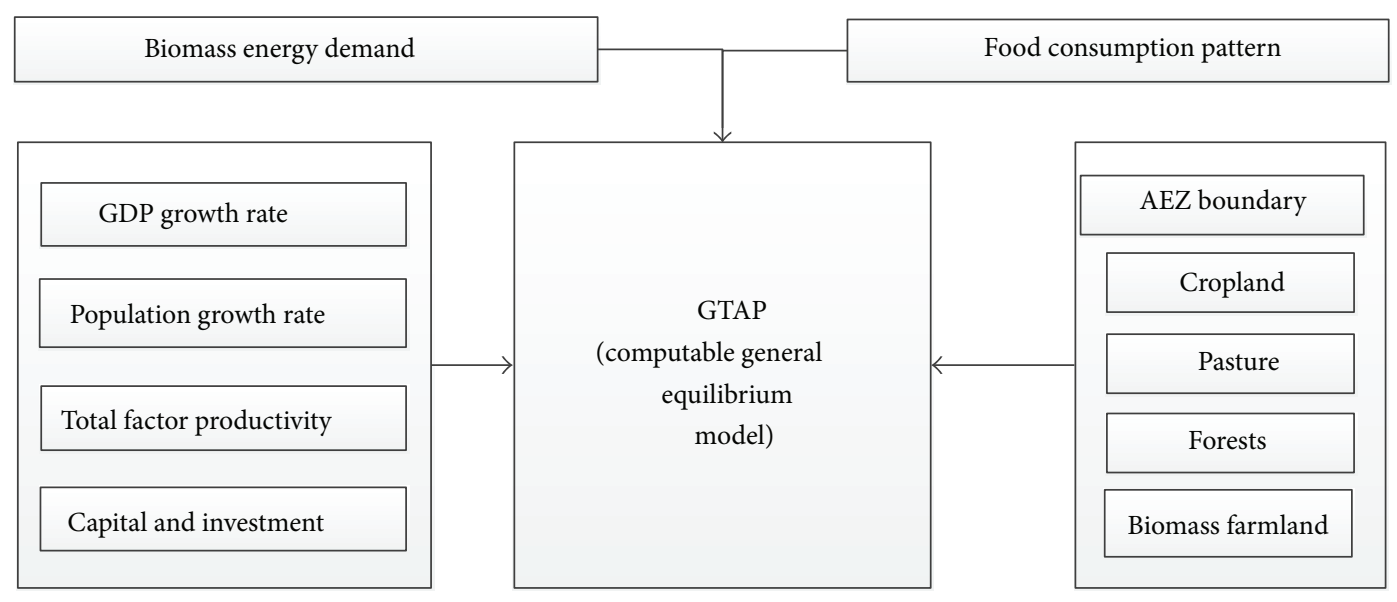

FIGURE 2: Framework of the GTAP-AEZ model.

TABLE 1: Description of RCPs.

\begin{tabular}{|c|c|c|}
\hline & Description & $\begin{array}{c}\text { Publication-IA } \\
\text { Model } \\
\end{array}$ \\
\hline CP8.5 & $\begin{array}{l}\text { Rising radiative forcing pathway } \\
\text { leading to } 8.5 \mathrm{~W} / \mathrm{m}^{2} \text { in } 2100\end{array}$ & $\begin{array}{c}\text { MESSAGE } \\
{[30]}\end{array}$ \\
\hline RCP6 & $\begin{array}{l}\text { Stabilization without overshoot } \\
\text { pathway to } 6 \mathrm{~W} / \mathrm{m}^{2} \text { at stabilization }\end{array}$ & AIM [31] \\
\hline $\mathrm{RCP} 4.5$ & $\begin{array}{l}\text { Stabilization without overshoot } \\
\text { pathway } 4.5 \mathrm{~W} / \mathrm{m}^{2} \text { at stabilization after } \\
2100\end{array}$ & GCAM [32] \\
\hline RCP2.6 & $\begin{array}{l}\text { Peak in radiative forcing at } \sim 3 \mathrm{~W} / \mathrm{m}^{2} \\
\text { before } 2100 \text { and decline }\end{array}$ & IMAGE [33] \\
\hline
\end{tabular}

(which can be compared to the original emissions of the IAMs) [34].

Two important characteristics of RCPs are reflected in their names. The word "representative" indicates that each of the RCPs represents a large set of scenarios in the various literature. In fact, as a set the RCPs should be compatible with the full range of emissions' scenarios available in the various current scientific literature, with and without the climate policy. The words "concentration pathway" means to emphasize that these RCPs are internally consistent sets of projections of the components of radiative forcing that are used in subsequent phases rather than the final new and fully integrated scenarios; that is, they are not a complete package of socio-economic, emission, and climate projections. The use of the word "concentration" instead of "emissions" also emphasizes that concentrations are used as the primary product of the RCPs and designed as inputs to climate models [35].

The RCP4.5 scenario is used in this study, under which the land use change is simulated with GCAM. Besides, the GTAP-AEZ model, which is similar to GCAM, is also used to analyze the land use structure in AEZs, and the results obtained with the two models were finally compared. The RCP4.5 scenario is a stabilization scenario in which the total radiative forcing is stabilized shortly after 2100 , without overshooting the long-run radiative forcing target level [36].
RCP4.5 includes long-term, global emissions of greenhouse gases, short-lived species, and land use-land cover in a global economic framework which stabilizes the radiative forcing at 4.5 Watts per square meter $\left(\mathrm{W} / \mathrm{m}^{2}\right)$, approximately $650 \mathrm{ppm}$ $\mathrm{CO}_{2}$-equivalent in the year 2100 without ever exceeding that value. The defining characteristics of this scenario are enumerated in Moss' papers [17, 18]. RCP 4.5 was updated from earlier GCAM scenarios to incorporate the historical emissions and land cover information and follows a costminimizing pathway to reach the target radiative forcing. The necessity to limit emissions in order to reach this target leads to the changes in the energy system, including shifts to electricity, lower emissions energy technologies, and the deployment of carbon capture and geologic storage technology. In addition, the RCP4.5 emission price is also applicable to the land use emissions. The simulated future emissions and land use were downscaled from the regional scale to the grid scale to facilitate the transfer to climate models. While there are many alternative pathways to achieve a radiative forcing level of $4.5 \mathrm{~W} / \mathrm{m}^{2}$, the application of the RCP4.5 provides a common platform for climate models to explore the response of the climate system to stabilize the anthropogenic components of radiative forcing.

\section{Results and Analysis}

The results indicate that the land use areas in different AEZs, which are obtained with the GCAM model and the GTAP-AEZ model, are generally consistent (Figure 3). The pastureland areas simulated with the two models differ most greatly, but they are still generally consistent in different AEZs. Besides, the results obtained with the GTAP-AEZ model and the GCAM model both show that the grassland is approximately equally distributed in different AEZs, but the grassland area in different AEZs differs a bit more greatly in the result obtained with the GCAM model. In addition, the results obtained with the two models show that the forestland is mainly located in AEZ9-AEZ12, while the shrubland and cropland are mainly in AEZ7-AEZ13. What is more, the built-up land, the area of which is the smallest, 


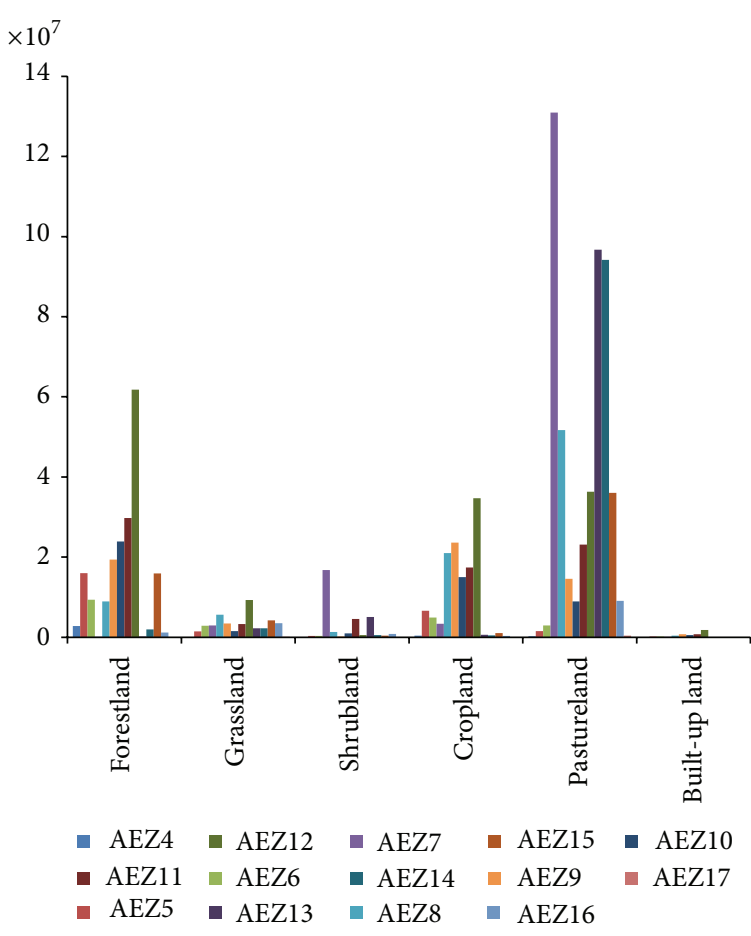

(a)

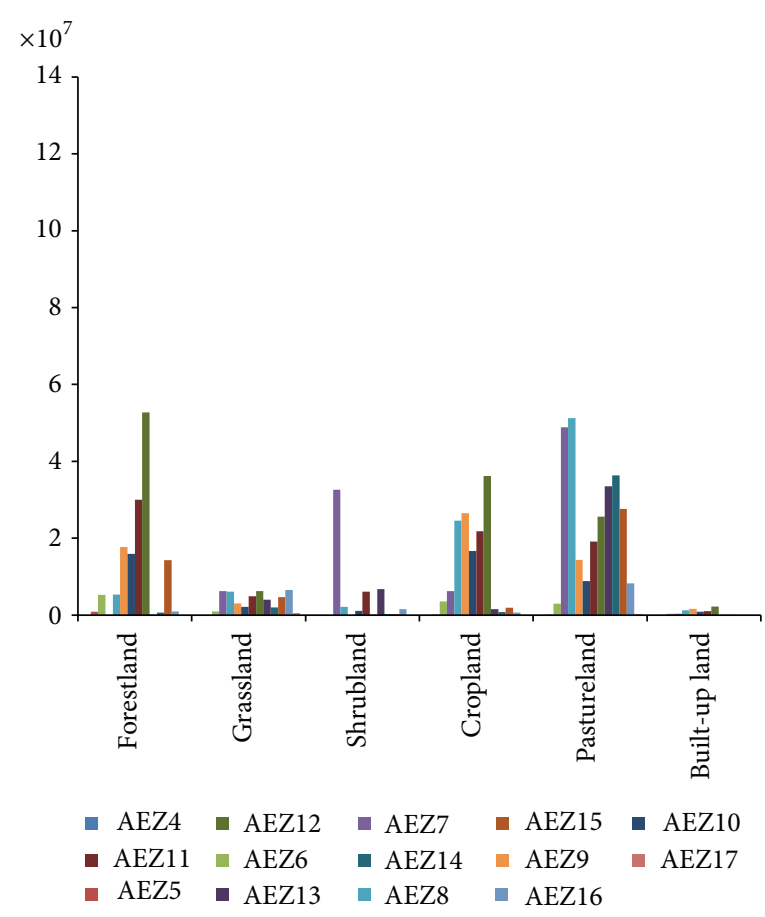

(b)

FIgURE 3: Simulated land use area in 14 AEZs in 2010 using the GCAM model (a) and GTAP-AEZ model (b) (unit: hectare).

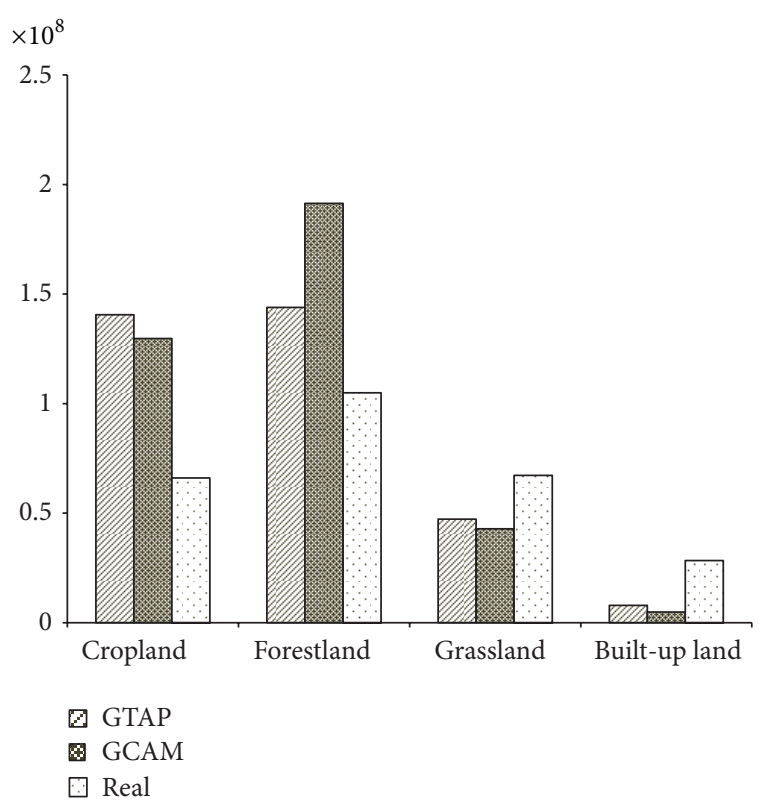

FIGURE 4: Comparison between the simulated and real land use areas in 2010 (unit: hectare).

is generally distributed in AEZ10. Through comparing the results obtained with the two models, it is found that the distribution of different land use types among AEZs is approximately consistent, but with some difference in the total areas of different land use types.

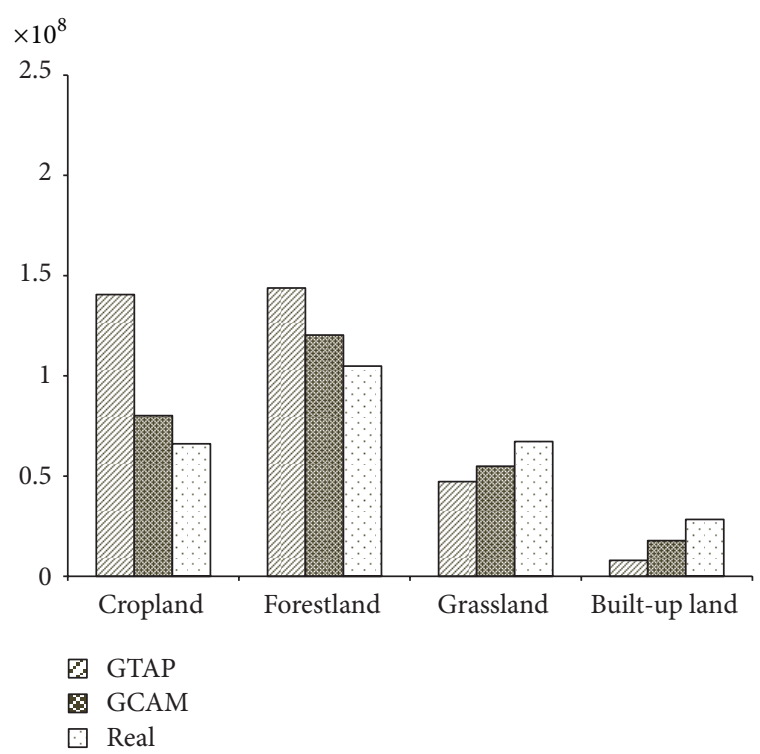

FIgUre 5: The comparison of land use area in China in 2010 simulated with the calibrated GCAM model, the GTAP model, and the real values (unit: hectare).

There is still some difference between the real land use area and that obtained with the two models, and the simulation result with the GTAP-AEZ model is better than that with the GCAM model (Figure 4). The result shows that the areas of cropland and forestry land simulated with 
TABLE 2: The adjustment of GCAM input parameters in 2010 (unit: $\%)$.

\begin{tabular}{lcc}
\hline Input parameters & Previous parameters & Adjusted parameters \\
\hline GDP growth & 10 & 10.4 \\
Labor growth & 0.4 & 0.4 \\
Capital growth & 12.6 & 12.8 \\
TFP growth & 0.9 & 1.1 \\
Population growth rate & 0.8 & 0.5 \\
\hline
\end{tabular}

the GCAM model and the GCAM model are far higher than the real one. The area of cropland obtained with the GCAM model and the GTAP-AEZ model is 2.13 and 1.96 times larger than the real one, respectively. However, the areas of grassland and built-up land simulated with the two models are both lower than real values. This indicates that there is still some inaccuracy in data of the land use structure, industry structure, and social economic situation of China in the global simulation. For example, the forest land should be divided into economic forest lands and ecological forest lands, but the forest land was not distinguished in this study, which leads to the significant difference between the simulated and real areas of the forest land.

There are an extremely complex socioeconomic structure and land use structure in China, both of which have changed greatly due to the rapid economic development of China and consequently made it very difficult to accurately simulate the land use change in China using models with static data. For instance, the estate price in China has fluctuated prominently during the past decades, but a static estate price was first used in the GCAM model in this study, which makes it obviously difficult to simulate the constantly changing industrial structure in China. Therefore, it is necessary to calibrate the models before simulating the land use change.

In order to more accurately simulate the change of the land use structure in China according to the reality of China and improve the precision of future scenario simulation, we calibrated the parameters of the GCAM model and the GTAP-AEZ model (Table 2). The influence of policy intervention was included in the models according to the specific national condition of China, and other parameters were also calibrated. In this study, the price of agricultural products was set to increase by 1.5 percent every year; TFP will increase by 0.1 percent, and the annual population growth rate will decrease from $0.8 \%$ to $0.5 \%$. The results indicate that the land use structure simulated with the calibrated GCAM model becomes much more accurate than it was and has more closely approached to that in the reality. Besides, the simulation accuracy with the calibrated GCAM model is much higher than that with the calibrated GTAP-AEZ model (Figure 5).

\section{Conclusion and Discussion}

This study simulated the land use change in China under the RCP 4.5 scenario with GCAM and GTAP-AEZ models and compared the simulated and real land use structures. Overall, the simulation results obtained with GCAM and
GTAP-AEZ are consistent, but also with some difference, and the land use structure simulated with GTAP-AEZ is to be more close to the real conditions in different AEZs than that obtained with GCAM. For example, the consistence between the forest land area simulated with GCAM and the real one reached more than $80 \%$, while that with GTAP-AEZ reached only $37 \%$. GCAM involves the driving factors of the rapid economic development, which makes the simulation more close to the reality. However, neither of the two models takes account of the impacts of policies on socioeconomic development, which also have great influence on the land use change. Therefore, it is necessary to calibrate the models through optimizing the model input parameters. When the models are calibrated through adjusting these socioeconomic parameters according to the specific conditions, the overall simulation accuracy of GCAM reached $82 \%$, while that of GTAP-AEZ also reached $60 \%$, indicating that it is possible and necessary to improve the simulation accuracy through optimizing input parameters of the models according to the specific conditions.

In recent decades, more and more land use simulation models have developed, but it is still a hard task to implement the calibration of input parameters of these model. In the study, the land use structure of China in 2010 under the RCP 4.5 climate change scenario was simulated with GCAM and GTAP-AEZ, both of which were further calibrated through adjusting the input parameters, focusing on comparing simulation accuracy of the two models. The result indicates that the areas of cropland and forest land simulated with the two models were higher than the real one, while the simulated areas of grassland and built-up land were lower than the real values, and the simulation accuracy was greatly improved after the model calibration. However, due to the uncertainties of climate change, economic development, and other factors, it is very difficult to accurately simulate the long-term land use change in the future, and therefore it is necessary to implement more in-depth research on how to optimize the parameters according to the specific conditions in the future.

\section{Conflict of Interests}

The authors declare that there is no conflict of interests regarding the publication of this paper.

\section{Acknowledgments}

This research was supported by the Key Project funded by the National Key Programme for Developing Basic Science in China (Grant no. 2010CB950900), National Natural Science Foundation of China (Grant no. 41071343), and the Key Projects in the National Science \& Technology Pillar Program (Grant no. 201311001-5).

\section{References}

[1] P. M. Vitousek, H. A. Mooney, J. Lubchenco, and J. M. Melillo, "Human domination of Earth's ecosystems," Science, vol. 277, no. 5325, pp. 494-499, 1997. 
[2] X. Deng, C. Zhao, and H. Yan, "Systematic modeling of impacts of land use and land cover changes on regional climate: a review," Advances in Meteorology, vol. 2013, Article ID 317678, 11 pages, 2013.

[3] E. F. Lambin, X. Baulies, N. E. Bockstael et al., "Land-use and land-cover change (LUCC), implementation strategy," IGBP Report 48, IHDP Report 10, IGBP, Stockholm, Sweden; IHDP, Bonn, Germany, 2000.

[4] B. L. Turner II, "Local faces, global flows: the role of land use and land cover in global environmental change," Land Degradation \& Rehabilitation, vol. 5, no. 2, pp. 71-78, 1994.

[5] J. Y. Liu and X. Z. Deng, "Progress of the research methodologies on the temporal and spatial process of LUCC," Chinese Science Bulletin, vol. 55, no. 14, pp. 1354-1362, 2010.

[6] S. Cao, C. Wu, and W. Yu, "Evaluation of land ecological service and its application in overall arrangement of land use," Bulletin of Soil and Water Conservation, vol. 20, no. 2, pp. 197-200, 2006.

[7] Q. Jiang, X. Deng, H. Yan, D. Liu, and R. Qu, "Identification of food security in the mountainous guyuan prefecture of China by exploring changes of food production," Journal of Food, Agriculture \& Environment, vol. 10, no. 1, pp. 210-216, 2012.

[8] X. Deng, F. Yin, Y. Lin, Q. Jin, and R. Qu, "Equilibrium analyses on structural changes of land uses in Jiangxi Province," Journal of Food, Agriculture \& Environment, vol. 10, no. 1, pp. 846-852, 2012.

[9] Y. Hu, Y. Liu, and X. Deng, "Relativity analysis on land use and land cover change and optimal allocation of land resources," Progress in Geography, vol. 23, no. 2, pp. 51-57, 2004.

[10] A. Flamenco-Sandoval, M. Martínez Ramos, and O. R. Masera, "Assessing implications of land-use and land-cover change dynamics for conservation of a highly diverse tropical rain forest," Biological Conservation, vol. 138, no. 1-2, pp. 131-145, 2007.

[11] X. Deng, H. Su, and J. Zhan, "Integration of multiple data sources to simulate the dynamics of land systems," Sensors, vol. 8, no. 2, pp. 620-634, 2008.

[12] Y. Cai, Y. Liu, Z. R. Yu, and P. H. Verburg, "Progress in spatial simulation of land use change-CLUE-s model and its application," Progress in Geography, vol. 23, no. 4, pp. 63-71, 2004.

[13] J. Y. Liu and X. Z. Deng, "Progress of the research methodologies on the temporal and spatial process of LUCC," Chinese Science Bulletin, vol. 55, no. 14, pp. 1354-1362, 2010.

[14] A. Brenkert, S. Kim, A. Smith, and H. Pitcher, "Model Documentation for the MiniCAM," U.S. Department of Energy, PNNL-14337, 2003.

[15] H. Lee, Incorporating Agro-Ecologically Zoned Land Use Data and Land-Based Greenhouse Gases Emissions into the GTAP Framework, Centre for Global Trade Analysis, Purdue University, West Lafayette, Ind, USA, 2005.

[16] J. M. Burniaux and H. L. Lee, "Modelling land use change in GTAP," 2005.

[17] R. Moss, M. Babiker, S. Brinkman, and E. Calvo, "Towards new scenarios for analysis ofemissions, climate change, impacts, and response strategies," IPCC Expert Meeting Report, Intergovernmental Panel on Climate Change, Geneva, Switzerland, 2008.

[18] R. H. Moss, J. A. Edmonds, K. A. Hibbard et al., "The next generation of scenarios for climate change research and assessment," Nature, vol. 463, no. 7282, pp. 747-756, 2010.

[19] M. Wise, K. Calvin, A. Thomson et al., "Implications of limiting $\mathrm{CO}_{2}$ concentrations for land use and energy," Science, vol. 324, no. 5931, pp. 1183-1186, 2009.
[20] J. Edmonds, M. Wise, H. Pitcher, R. Richels, T. Wigley, and C. MacCracken, "An integrated assessment of climate change and the accelerated introduction of advanced energy technologies: an application of MiniCAM 1.0," Mitigation and Adaptation Strategies for Global Change, vol. 1, no. 4, pp. 311-339, 1997.

[21] J. Edmonds and J. Reilly, Global Energy: Assessing the Future, Oxford University Press, New York, NY, USA, 1985.

[22] R. D. Sands and J. A. Edmonds, "Climate change impacts for the conterminous USA: an integrated assessment-part 7: economic analysis of field crops and land use with climate change," Climatic Change, vol. 69, no. 1, pp. 127-150, 2005.

[23] R. D. Sands and M. Leimbach, "Modeling agriculture and land use in an integrated assessment framework," Climatic Change, vol. 56, no. 1-2, pp. 185-210, 2003.

[24] T. M. L. Wigley and S. C. B. Raper, "Implications for climate and sea level of revised IPCC emissions scenarios," Nature, vol. 357, no. 6376, pp. 293-300, 1992.

[25] M. Hulme, T. Jiang, and T. M. L. Wigley, SCENGEN: A Climate Change Scenario Generator, a Software User Manual, Climatic Change Research Unit, School of Environmental Sciences, University of East Anglia, Norwich, UK, 1995.

[26] J. M. Burniaux and T. Truong, "GTAP-E: an energyenvironmental version of the GTAP model," GTAP Technical Paper 16, Center for Global Trade Analysis, Purdue University, West Lafayette, Ind, USA, 2001.

[27] E. Ianchovichina and R. McDougall, "Structure of dynamic GTAP," GTAP Technical Paper 17, Center for Global Trade Analysis, 2001, http://www.gtap.org/.

[28] X. Deng, J. Han, and F. Yin, "Net energy, $\mathrm{CO}_{2}$ emission and land-based cost-benefit analyses of Jatropha biodiesel: a case study of the Panzhihua region of Sichuan province in China," Energies, vol. 5, pp. 2150-2164, 2012.

[29] A. Golub, Projecting the global economy to 2025: a dynamic general equilibrium approach [Ph.D. thesis], Purdue University, 2006.

[30] K. Riahi, A. Grübler, and N. Nakicenovic, "Scenarios of longterm socio-economic and environmental development under climate stabilization," Technological Forecasting and Social Change, vol. 74, no. 7, pp. 887-935, 2007.

[31] Y. Hijioka, Y. Matsuoka, H. Nishimoto, T. Masui, and M. Kainuma, "Global GHG emission scenarios under GHG concentration stabilization targets," Journal of Global Environment Engineering, vol. 13, pp. 97-108, 2008.

[32] S. J. Smith and T. M. L. Wigley, "Multi-gas forcing stabilization with minicam," The Energy Journal, vol. 27, pp. 373-391, 2006.

[33] D. P. van Vuuren, B. Eickhout, P. L. Lucas, and M. G. J. den Elzen, "Long-term multi-gas scenarios to stabilise radiative forcingexploring costs and benefits within an integrated assessment framework," Energy Journal, vol. 27, pp. 201-233, 2006.

[34] K. A. Hibbard, G. A. Meehl, P. M. Cox, and P. Friedlingstein, "A strategy for climate change stabilization experiments," Eos, vol. 88 , no. 20, pp. 217-221, 2007.

[35] F. Wu, X. Deng, F. Yin, and Y. Yuan, "Projected changes of grassland productivity along the representative concentration pathways during 2010-2050 in China," Advances in Meteorology, vol. 2013, Article ID 812723, 9 pages, 2013.

[36] J. Liu, J. Zhan, and X. Deng, "Spatio-temporal patterns and driving forces of urban land expansion in China during the economic reform era," Ambio, vol. 34, no. 6, pp. 450-455, 2005. 

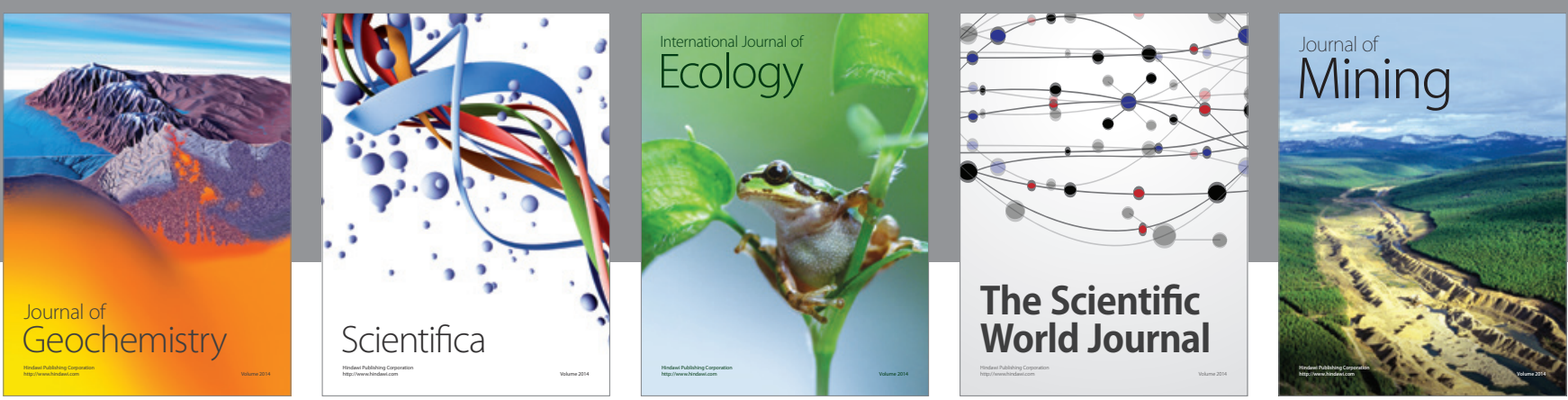

The Scientific World Journal
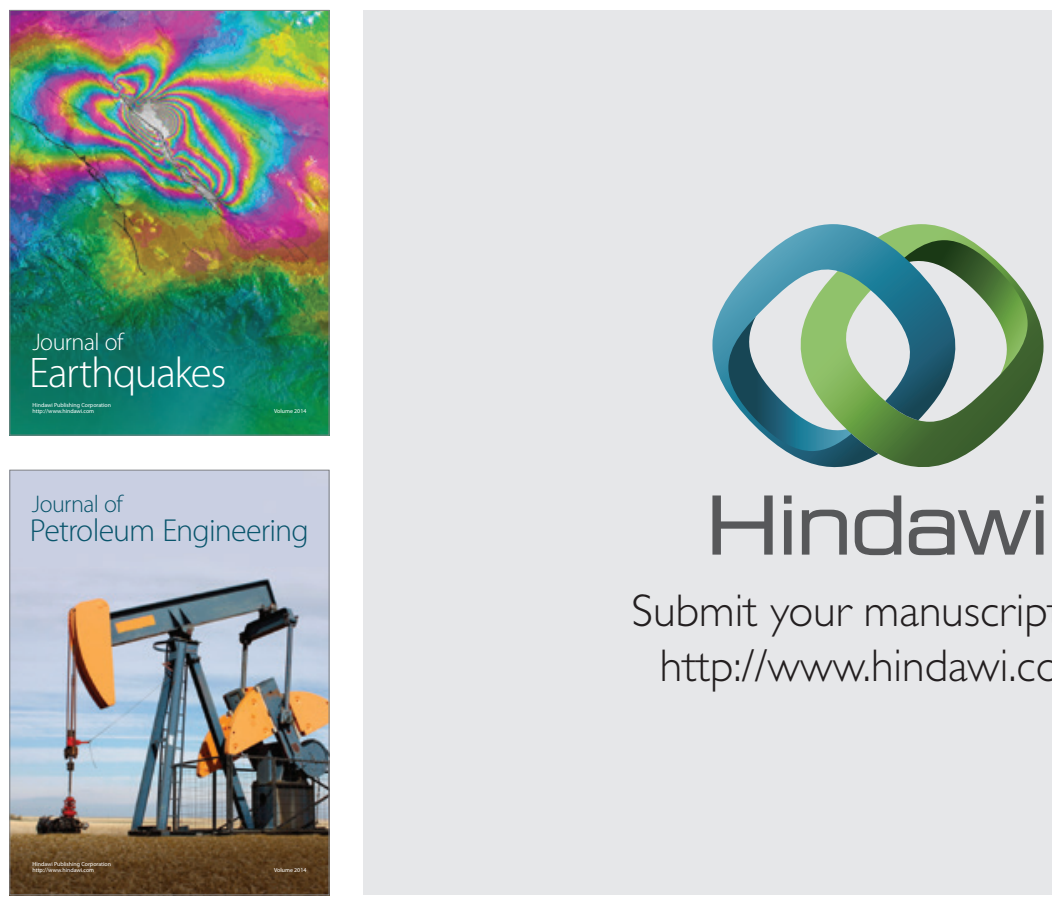

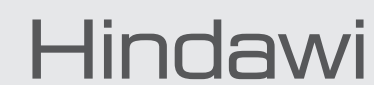

Submit your manuscripts at

http://www.hindawi.com
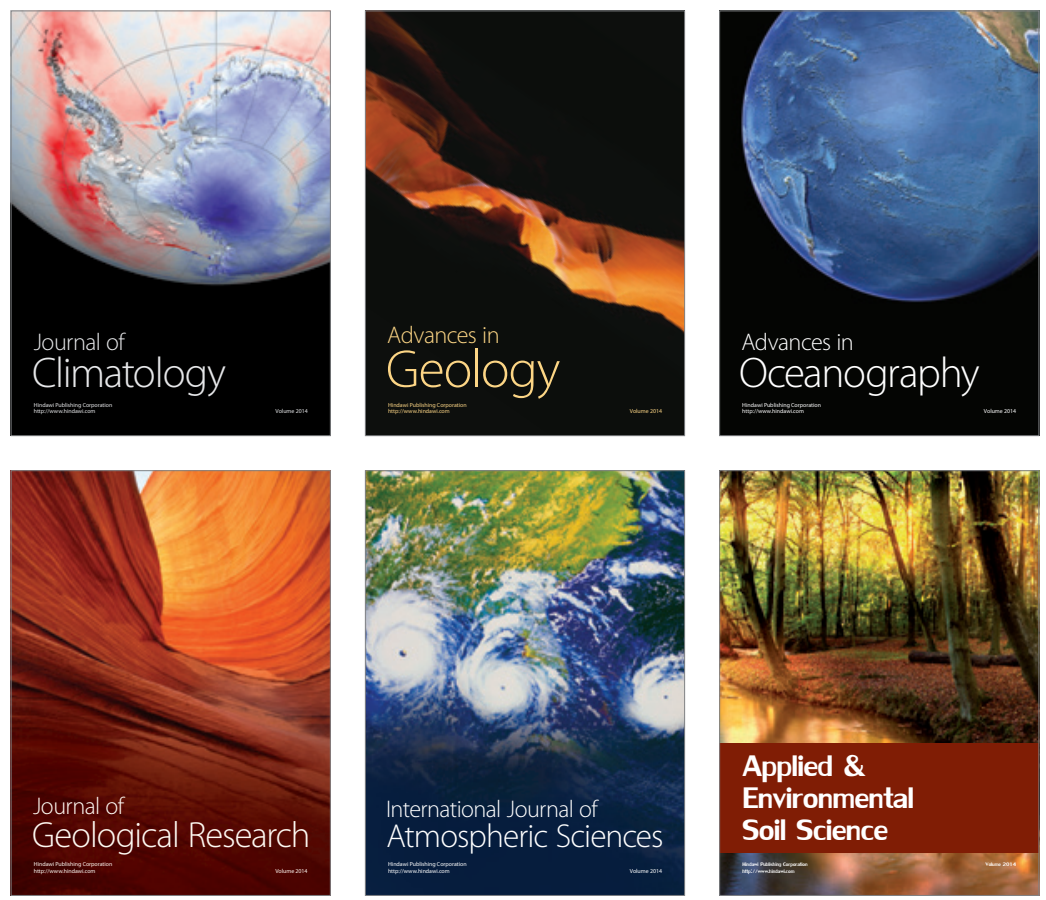
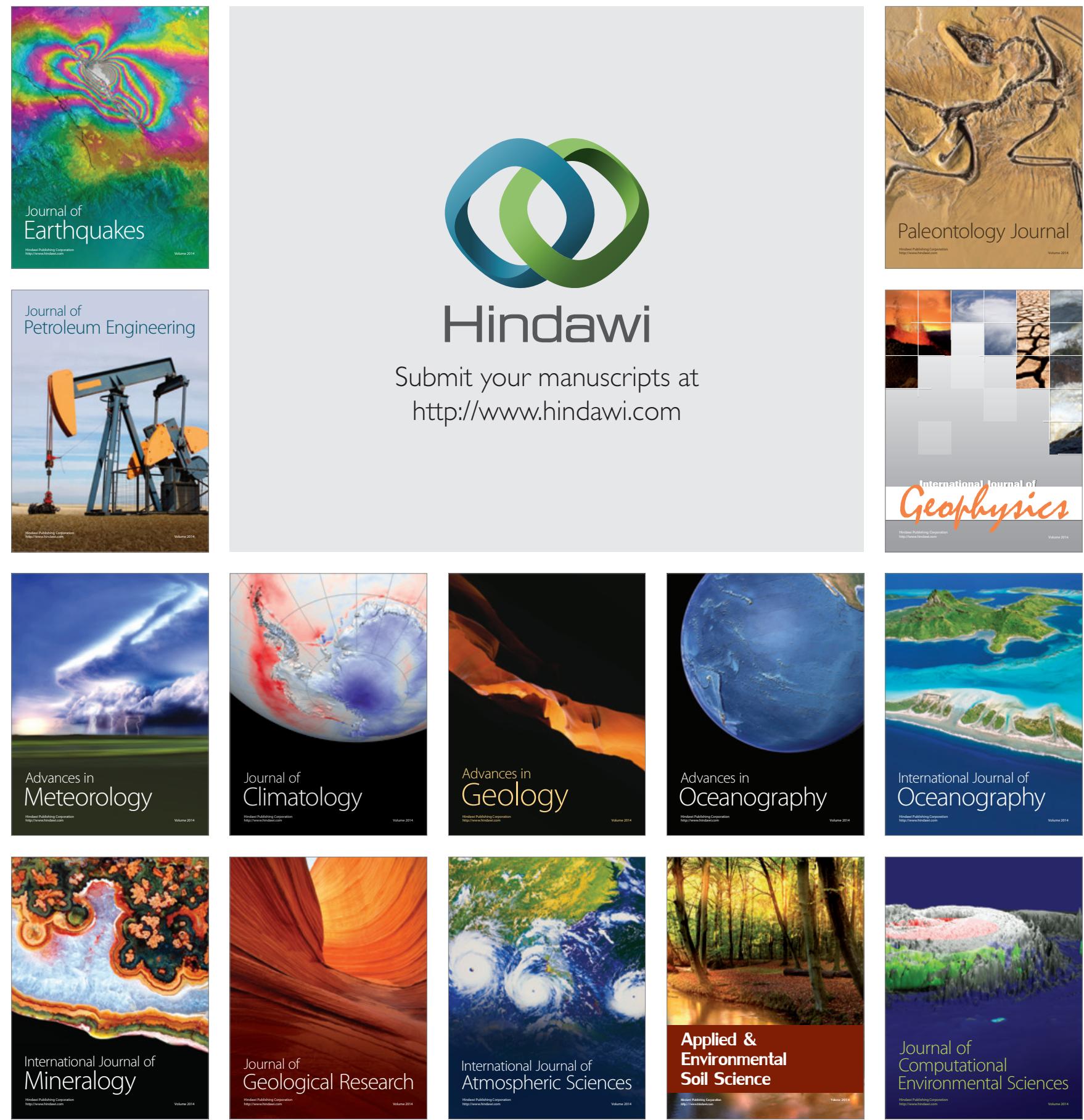